\title{
GOLD 2017 on the way to a phenotypic approach? Analysis from the Phenotypes of COPD in Central and Eastern Europe (POPE) Cohort
}

\author{
To the Editor:
}

Recently, the Global Initiative for Chronic Obstructive Lung Disease (GOLD) released a revised consensus report (2017 GOLD Report) [1] in which the formerly defined ABCD classification of patients with COPD has been refined. The 2011 GOLD Report and its 2016 Update classified patients on the basis of three variables, i.e. the symptom burden, lung function impairment and exacerbations [2], now the A-D groups are defined solely on the basis of symptoms and history of exacerbations - thus recognising the limitations of the forced expiratory volume in $1 \mathrm{~s}$ (FEV1) in influencing therapeutic decisions in COPD [1]. The obvious consequence of the new classification is a shift of a proportion of patients from the $\mathrm{C}$ to the A group, and from the $\mathrm{D}$ to the $\mathrm{B}$ group. Nevertheless, the magnitude of such redistribution remains unknown.

The aims of the present study were 1) to analyse the effects of applying the new GOLD 2017 recommendations on the distribution of the A-D groups, and 2) to foresee the possible implications of the new GOLD recommendations on the maintenance therapy for COPD. For this purpose, we used data from the POPE (Phenotypes of COPD in Central and Eastern Europe) study, which is an international, multicentre, observational and cross-sectional study of 3361 COPD subjects in 10 countries in Central and Eastern Europe (CEE) (ClinicalTrials.gov identifier NCT02119494) [3]. The study provided numerous data, including ABCD distribution based on the 2016 GOLD Report and the distribution of predefined clinical COPD phenotypes [3]. Its rationale, organisational structure and methodology have been reported in more detail previously [4]. The study protocol, informed consent and patient information were submitted to ethics committees in the respective countries and to regulatory agencies, where required; as a result, all patients were requested to provide their informed consent (except those in Poland, where formal ethics committee approval and written informed consent was not required due to the observational nature of the study) [3].

Application of the new GOLD 2017 recommendations profoundly affected the distribution of patients in the A-D groups. Classified according to recommendations of the 2016 GOLD Report, 287 (8.5\%) of 3361 COPD patients were in class A, 1023 (30.5\%) in class B, 125 (3.7\%) in class C and $1926(57.3 \%)$ were in class D. Such distribution was consistent with reports of other groups [5, 6]. In contrast, when using the assessment according to the GOLD 2017 recommendations, $346(10.3 \%)$ of the COPD patients were in class A, 1709 (50.8\%) in class B, 66 (2.0\%) in class C and 1240 (36.9\%) in class D (figure 1). Thus, the new classification led to two 'vertical' shifts in the distribution of COPD patients: 59 patients $(1.8 \%$ of the entire cohort and $47.2 \%$ of group C) moved from group C to group A, and 686 patients $(20.4 \%$ of the entire cohort and $35.6 \%$ of group D) moved from group D to group B. This 'vertical' shift from D to B reflects the situation in which, according to the GOLD 2016 recommendations, only 464 (24.1\%) of 1926 patients were in group D because of frequent exacerbations (of these 380 (82\%) with two or more exacerbations in the previous year), but $686(35.6 \%)$ were because of poor lung function $\left(\mathrm{FEV}_{1}<50 \%\right)$, and the remaining 776 (40.3\%) patients fulfilled both criteria (of these $675(87 \%)$ had two or more exacerbations in the previous year). Thus, according to the revised $\mathrm{ABCD}$ classification, more than a third of patients formerly classified as 'D' solely on the basis of poor lung function moved from the $\mathrm{D}$ to the $\mathrm{B}$ group.

@ERSpublications

The distribution of patients based on exacerbations solely is the most profound consequence of the 2017 GOLD Report http://ow.ly/4UJa309fLbM

Cite this article as: Tudoric N, Koblizek V, Miravitlles M, et al. GOLD 2017 on the way to a phenotypic approach? Analysis from the Phenotypes of COPD in Central and Eastern Europe (POPE) Cohort. Eur Respir J 2017; 49: 1602518 [https://doi.org/10.1183/13993003.02518-2016]. 
FIGURE 1 Comparison of the distribution of COPD patients using the Global Initiative for Chronic Obstructive Pulmonary Disease (GOLD) groups A-D 2016 and 2017 classifications; $\mathrm{n}=3361$

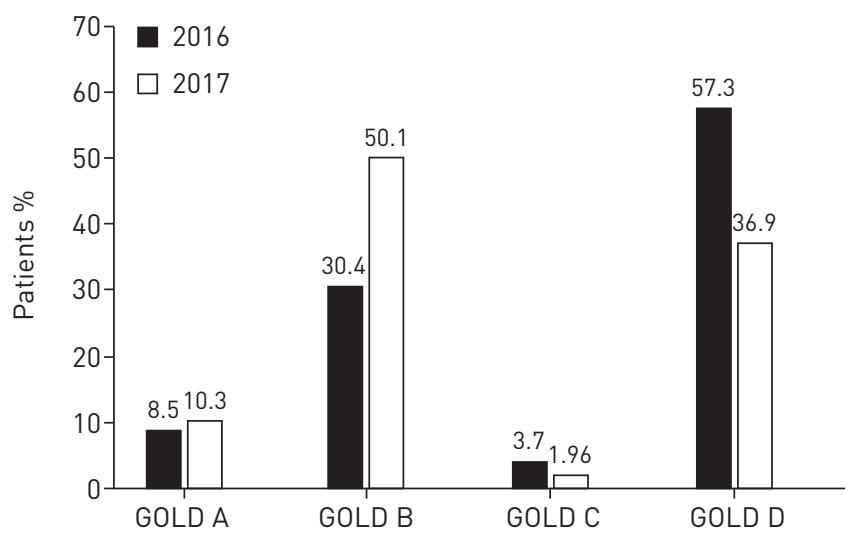

Interestingly, in the COPDgene, Copenhagen and ECLIPSE cohorts, the proportions of patients classified as ' $\mathrm{D}$ ' solely based on their poor lung function were even higher than the POPE cohort $(64 \%, 79 \%$ and $63 \%$, respectively) [7], implying that the revised assessment of COPD and the new A-D classification may affect an even higher proportion of COPD patients than that observed in the POPE cohort. The higher proportion of exacerbators in the POPE cohort is likely to reflect a higher prevalence of risk factors for exacerbations in CEE such as active smoking, worse FEV1, more comorbidities and/or less adequate or intense treatment. Analyses of these factors are beyond the scope of the present study.

A total of $490(71.5 \%)$ of 686 patients who shifted from the D to the B group were treated with inhaled corticosteroids (ICS). Of these, $391(79.8 \%)$ used ICS as a part of triple ICS+long-acting beta-agonist (LABA)+ long-acting muscarinic receptor agonist (LAMA) treatment, 92 (18.8\%) used ICS in combination with LABA, and only two $(0.4 \%)$ used ICS in combination with LAMA, and five (1.0\%) patients used ICS as monotherapy. Application of the GOLD 2017 recommendations might lead to the discontinuation of ICS in some of these 490 patients who shifted from D to B because of the lack of exacerbations. Of note, GOLD 2017 recognises that FEV1 can be used to guide therapy in selected circumstances and we believe, in agreement with others [8], that an individualised approach in de-escalation of ICS should be applied.

Dual bronchodilation therapy with LABA and LAMA, which is the recommended first-line treatment for highly symptomatic patients in groups B and D in the new GOLD recommendations, was used only by 136 $(11.0 \%)$ of patients in the original (i.e. based on GOLD 2016 recommendations) group D. Importantly, 126 (18.4\%) of patients who shifted from group D to group B had very severe bronchial obstruction with FEV $1 \leqslant 30 \%$. This might have important clinical implications if these patients, being classified as group B, were prescribed a single long-acting bronchodilator only. However, acknowledging that GOLD 2017 suggests that spirometry may influence treatment decisions in patients with discrepancy between spirometry and the level of symptoms, we believe that the majority of patients who shifted from group D to group $\mathrm{B}$ and had poor lung function should be treated with dual bronchodilation.

One more observation deserves attention. Out of 130 patients initially in group D fulfilling the criteria for the asthma-COPD overlap syndrome (ACOS) [9], 97 (74.6\%) remained in category D but $33(25.4 \%)$ moved to group B after reclassification based on GOLD 2017. Despite the previous GINA/GOLD report [10], ACOS has not been included in the new classification for treatment in GOLD 2017 and it is only mentioned in the text as a factor to choose a treatment option containing ICS in group D. Therefore, patients moving to group B might discontinue ICS with potentially harmful consequences.

In conclusion, we consider the 'vertical' shift reflecting the distribution of patients based on exacerbations solely as the most profound clinical consequence of the new 2017 GOLD report. In proposing a distribution of COPD patients into exacerbators and non-exacerbators ( $\mathrm{CD}$ versus $\mathrm{AB}$ ), the new GOLD classification seems to be much closer to the phenotypic approach, and on the way to individualised medicine. 'Horizontal' division (A versus B; C versus D) may affect the therapeutic decisions to a lower degree, and will be probably reflected in different need for rescue medication. However, the decision for introducing other recommended treatments (roflumilast, ICS, azithromycin) is most likely to be based on phenotype (chronic bronchitis, ACOS, chronic infection) in addition to CAT scores and dyspnoea. As shown in our present study, accurate adherence to the new GOLD 2017 Report will likely promote dual bronchodilator treatments as the core gold standard therapy for majority of patients with COPD, significantly narrowing the use of ICS $[11,12]$. 
Neven Tudoric ${ }^{1}$, Vladimir Koblizek ${ }^{2}$, Marc Miravitlles ${ }^{3}$, Arschang Valipour ${ }^{4}$, Branislava Milenkovic ${ }^{5}$, Adam Barczyk ${ }^{6}$, Attila Somfay, Kirill Zykov, Kosta Kostov, Zuzana Zbozinkova ${ }^{8}$, Michal Svoboda ${ }^{10}$, Jurij Sorli $^{11}$, Alvils Krams ${ }^{12}$ and Ruzena Tkacova ${ }^{13}$

${ }^{1}$ School of Medicine Zagreb, University Hospital Dubrava, Zagreb, Croatia. ${ }^{2}$ Department of Pneumology, University Hospital Hradec Kralove, Faculty of Medicine in Hradec Kralove, Charles University in Prague, Hradec Kralove, Czech Republic. ${ }^{3}$ Pneumology Department, Hospital Universitari Vall d'Hebron, CIBER de Enfermedades Respiratorias (CIBERES), Barcelona, Spain. ${ }^{4}$ Department of Respiratory and Critical Care Medicine, Ludwig-Boltzmann-Institute for COPD and Respiratory Epidemiology, Otto-Wagner-Spital, Wien, Austria. ${ }^{5}$ Clinic for Pulmonary Diseases, Clinical Centre of Serbia, Faculty of Medicine, Belgrade, Serbia. ${ }^{6}$ Department of Pneumology, School of Medicine in Katowice, Medical University of Silesia, Katowice, Poland. ${ }^{7}$ Department of Pulmonology, University of Szeged, Deszk, Hungary. ${ }^{8}$ Laboratory of Pulmonology, Moscow State University of Medicine and Dentistry named after A.I. Evdokimov, Moscow, Russian Federation. ${ }^{9}$ Clinic of Pulmonary Diseases, Military Medical Academy, Sofia, Bulgaria. ${ }^{10}$ Institute of Biostatistics and Analyses, Faculty of Medicine, Masaryk University, Brno, Czech Republic. ${ }^{11}$ Pulmonary Department, Topolsica Hospital, Topolsica, Slovenia. ${ }^{12}$ Faculty of Medicine, University of Latvia, Riga, Latvia. ${ }^{13}$ Department of Respiratory Medicine and Tuberculosis, Faculty of Medicine, P.J. Safarik University, Kosice, Slovakia.

Correspondence: Ruzena Tkacova, Department of Respiratory Medicine and Tuberculosis, Faculty of Medicine, P. J. Safarik University, Kosice, Slovakia. E-mail: ruzena.tkacova@upjs.sk

Received: Dec 222016 | Accepted after revision: Jan 182017

This study is registered at www.clinicaltrials.gov with identifier number NCT02119494.

Support statement: Supported by an unrestricted research grant from Boehringer Ingelheim RCV GmbH \& Co. KG, which provided partial support for this study but had no influence on the rationale, methodology, or analysis. Funding information for this article has been deposited with the Crossref Funder Registry.

Conflict of interest: Disclosures can be found alongside this article at erj.ersjournals.com

\section{References}

1 Global Strategy for the Diagnosis, Management and Prevention of COPD, Global Initiative for Chronic Obstructive Lung Disease (GOLD) 2017. http://goldcopd.org Date last accessed: January 8, 2017.

2 Global Strategy for the Diagnosis, Management and Prevention of COPD, Global Initiative for Chronic Obstructive Lung Disease (GOLD) 2016. http://goldcopd.org/global-strategy-diagnosis-management-prevention-copd-2016/ Date last updated: February 1, 2016. Date last accessed: May 26, 2016.

3 Koblizek V, Milenkovic B, Barczyk A, et al. Phenotypes of COPD patients with a smoking history in Central and Eastern Europe - the POPE Study. Eur Respir J 2015; 46: Suppl. 59, PA393.

4 Zbozinkova Z, Barczyk A, Tkacova R, et al. POPE study: rationale and methodology of a study to phenotype patients with COPD in Central and Eastern Europe. Int J Chron Obstruct Pulmon Dis 2016; 11: 611-622.

5 Jones PW, Nadeau G, Small M, et al. Characteristics of a COPD population categorised using the GOLD framework by health status and exacerbations. Respir Med 2014; 108: 129-135.

6 Worth H, Buhl R, Criée CP, et al. The 'real-life' COPD patient in Germany: The DACCORD study. Respir Med 2016; 111: 64-71.

7 Agusti A, Hurd S, Jones P, et al. FAQs about the GOLD 2011 assessment proposal of COPD: a comparative analysis of four different cohorts. Eur Respir J 2013; 42: 1391-1401.

8 Kaplan AG. Applying the wisdom of stepping down inhaled corticosteroids in patients with COPD: a proposed algorithm for clinical practice. Int J Chron Obstruct Pulmon Dis 2015; 10: 2535-4258.

9 Sin DD, Miravitlles M, Mannino DM, et al. What is asthma-COPD overlap syndrome (ACOS)? Towards a consensus definition from a roundtable discussion. Eur Respir J 2016; 48: 664-673.

10 Global Initiative for Asthma and Global Initiative for Chronic Obstructive Pulmonary Disease. 2015 Asthma, COPD and Asthma-COPD Overlap Syndrome (ACOS) http://ginasthma.org/asthma-copd-and-asthma-copdoverlap-syndrome-acos/ Date last accessed: January 8, 2017.

11 Wedzicha J, Banerji D, Chapman KR, et al. Indacaterol-Glycopyrronium versus Salmeterol-Fluticasone for COPD. N Engl J Med 2016; 374: 2222-2234.

12 Beeh KM, Burgel PR, Franssen FM, et al. How do dual long-acting bronchodilators prevent exacerbations of chronic obstructive pulmonary disease? Am J Respir Crit Care Med 2016; in press [https://doi.org/10.1164/rccm. 201609-1794CI]. 